\title{
An Improved Safety Device for Electric Chainsaws
}

\author{
Sirio R. S. Cividino \\ Department of Agriculture and Environmental Sciences (DISA) \\ University of Udine, Via delle Scienze 208, Udine, Italy \\ Franco Blanchini \\ Department of Mathematics and Computer Science (DIMI) \\ University of Udine, Via delle Scienze 208, Udine, Italy \\ Rosario Lombardo \\ Department of Mathematics and Computer Science (DIMI) \\ University of Udine, Via delle Scienze 208, Udine, Italy
}

Daniele Dell'Antonia

Department of Agriculture and Environmental Sciences (DISA)

University of Udine, Via delle Scienze 208, Udine, Italy

\section{Tihana D. Vujinovic}

Department of Agriculture and Environmental Sciences (DISA)

University of Udine, Via delle Scienze 208, Udine, Italy

\section{Olga Malev}

Department of Agriculture and Environmental Sciences (DISA)

University of Udine, Via delle Scienze 208, Udine, Italy

\section{Rino Gubiani}

Department of Agriculture and Environmental Sciences (DISA)

University of Udine, Via delle Scienze 208, Udine, Italy

Copyright (C) 2015 Sirio R. S. Cividino et al. This article is distributed under the Creative Commons Attribution License, which permits unrestricted use, distribution, and reproduction in any medium, provided the original work is properly cited. 


\begin{abstract}
The chainsaw is a portable machine used for multi-purpose operations and can be used by professional and non-professional workers. Forestry and related tree operations represent one of the most hazardous working sectors of human activity. At the moment operations with chainsaws are conducted by all persons and are not solely restricted to professional lumberjacks. Serious or lethal lesions, due to the use of manual or electric chainsaws, are often encountered by emergency doctors or forensic pathologists. Such serious accidents often occur during occupational activities and are essentially due to kickback, uncorrected use of the tool and in case of lost implement control due to falling or slipping of the operator.

We developed and adopted an innovative safety device able to stop an electric chainsaw when needed. The device is based on a Wiimote controller (Nintendo ${ }^{\mathrm{TM}}$ ) which includes two accelerometers and two gyroscopes for detection of rotation and inclination. A Bluetooth wireless technology is used to transfer data to a portable computer. Collected data about linear and angular acceleration are filtered by an algorithm based on the Euclid norm which differentiates between normal and dangerous chainsaw movements. The results showed a good response of the safety device which sent an alarm signal when a dangerous situation occurred in order to stop the cutting chain. The device demonstrated correct behavior in all tested dangerous situations. We encourage extending its use to chainsaws with combustion engine, as well as to other portable equipment used in agriculture and forestry operations. For these applications the safety device was also patented.
\end{abstract}

Keywords: Safety, Chainsaw, Fatal injuries, Electronic device

\title{
1 Introduction
}

The chainsaw is a portable machine used for multi-purpose operations such as felling trees, limbing or cutting branches off the log, wood preparation or pruning tree and can be used by professional and un-professional users. At the moment all operations related to the use of chainsaws are conducted by different people and are not solely restricted to professional lumberjacks. Today, over 300,000 chainsaws are sold annually in Italy, while several millions of older models are still in use (data relative to the period 2007-2012). In Italy, overall accidents due to chainsaw use were mostly related to non-professional workers $(59.9 \%)$ than to others [3]. The United States (U.S.) Bureau of Labor Statistics reported that logging caused $26 \%$ more frequent injuries than general industry activities [4]. In the South-eastern U.S. a study showed that manual chainsaw limbing, i.e. the cutting of branches from stems in felled trees was the most hazardous activity during partially mechanized logging operations [12]. In Lousiana, a study showed that tools and equipment (including chainsaw) were responsible for 19\% of the 
injuries to the body in the logging sector [4]. Accident rates in Sweden among chainsaw operators have been reported to be four times higher than among logging-machine operators [5]. A German study (1994-1995) found that about $15 \%$ of all injuries to forestry workers were the direct result of chainsaws use [6].

In Italy, Spinelli (2010) reported that operators often do not employ a safe technique for starting chainsaws, and do not use personal protection equipment (PPE) in proper manner. In general, accidents data overview showed the chainsaw accidents have very high frequency rate, even more than other operations as a skidding, tending or intrinsic workplace conditions.

Modern chainsaws incorporate numerous safety features to protect the operator from kickback (i.e. the swift reaction upward movement of the chainsaw bar, especially when used with its tip or "nose") and other hazardous events (particularly when the operator falls down losing the control of the implement). However, such features may be ineffective when correct working procedures are overlooked or even ignored (which often is the case for unprofessional operators).

The kick-back energy and probability increase with increasing radius of the cutter-bar end and poor sharpening or incorrect depth-gauges [7]. The kick-back energy was measured by some researcher as well as the period when such events occur [11]. However, even the newest models possess some inherent danger associated with their usage that could result in serious and sometime fatal injuries. Serious or lethal lesions due to the use of manual or electric chainsaws are often observed by emergency doctors or forensic pathologists. Such serious accidents often occur during occupational activities and more rarely during suicidal events. For this kind of accidents, safety protection is possible only if the cutting chain is stopped because often the helmet is not sufficient to protect from this kind of accident. The cutting chain is stopped only by activation of the chain brake.

Many researchers have tried to set up a safety system designed to stop the chainsaw when the operator is using the chainsaw in a dangerous mode. One specific system proposed a capacitive sensor which detects human proximity near the guide bar and chain of the chainsaw. The capacitance sensors operate using a carrier frequency method and the developed system provides information about human proximity every $0.2 \mathrm{~s}$ and hence enables the control unit to react in real time. The developed system senses human proximity up to $15 \mathrm{~cm}$ from the chainsaw [13] and successfully distinguishes between proximity of the human body and wood.

In other recent study it was set up a brake on the electric chainsaw where the electric motor is an electronically commutated electric motor having at least three coil windings. At least one of the run-down and kickback brakes function is provided by means of a control circuit comprising a brake switch (14) associated with each of said at least one of the run-down and kickback brake and control means adapted to disconnect a driving voltage from each of said motor coil windings except at least one of them and apply a controlled resistive connection across the each of said motor coil windings.

At the moment, none of these systems reached commercial development, probably due to false response patterns that may decrease the work capacity of the 
operator. Only Husqvarna has adopted a system called TrioBrake ${ }^{\mathrm{TM}}$; which is a safety system where the chain brake can be activated in a third way - with the right hand besides the two custom available ways (i.e. with the left wrist and through the inertia function). TrioBrake ${ }^{\mathrm{TM}}$ can provide extra protection under situations where a regular chain brake would fail to provide adequate protection. This system influences the worker to assume a more ergonomic position with its body.

The objective of this study was to develop an innovative and integrated safety system for electric chainsaws.

\section{Materials and methods}

A new device capable of stopping the cutting chain was developed and adapted for an electric chainsaw. The development aims for an efficient use of this safety device included:

a) the device must block the cutting chain when a mistake in the chainsaw behavior is identified;

b) the device can be adopted in other handheld power equipment (drills, hedge trimmers), including chainsaws powered by 2 -stroke engines;

c) the device must have an overall low cost.

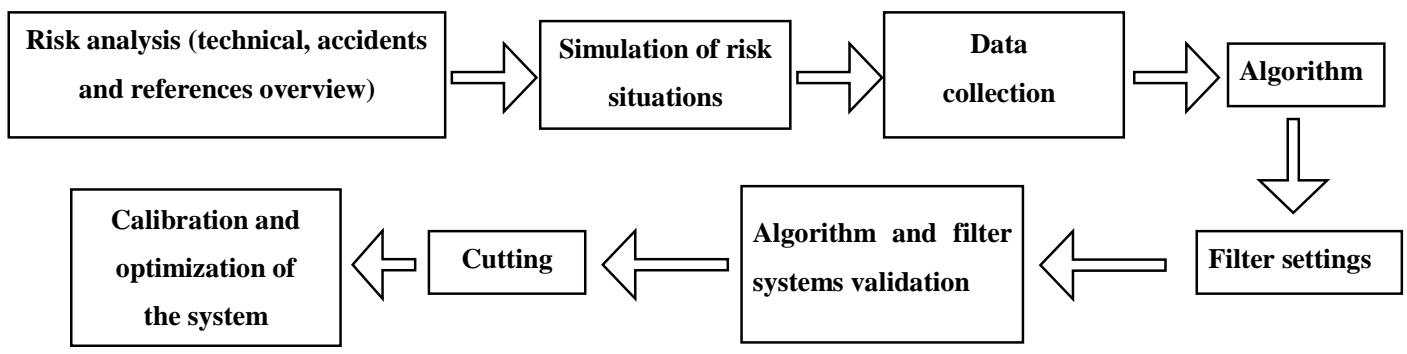

Figure 1 - The flow chart with the experimental set-up.

The device is based on a Wiimote controller (Nintendo ${ }^{\mathrm{TM}}$ ) which includes two accelerometers and two gyroscopes for rotation and inclination detection and in this way solves the steps under b) and c).

The main problem in the aim a) is to identify the mistakes in the chainsaw behavior and to solve these issues we had follow the path presented in Fig. 2.

A Bluetooth wireless technology was used to transfer all data to a portable computer. The data collected about linear and angular acceleration were filtered by an algorithm based on the Euclid norm capable of distinguishing between normal and dangerous chainsaw movements. 


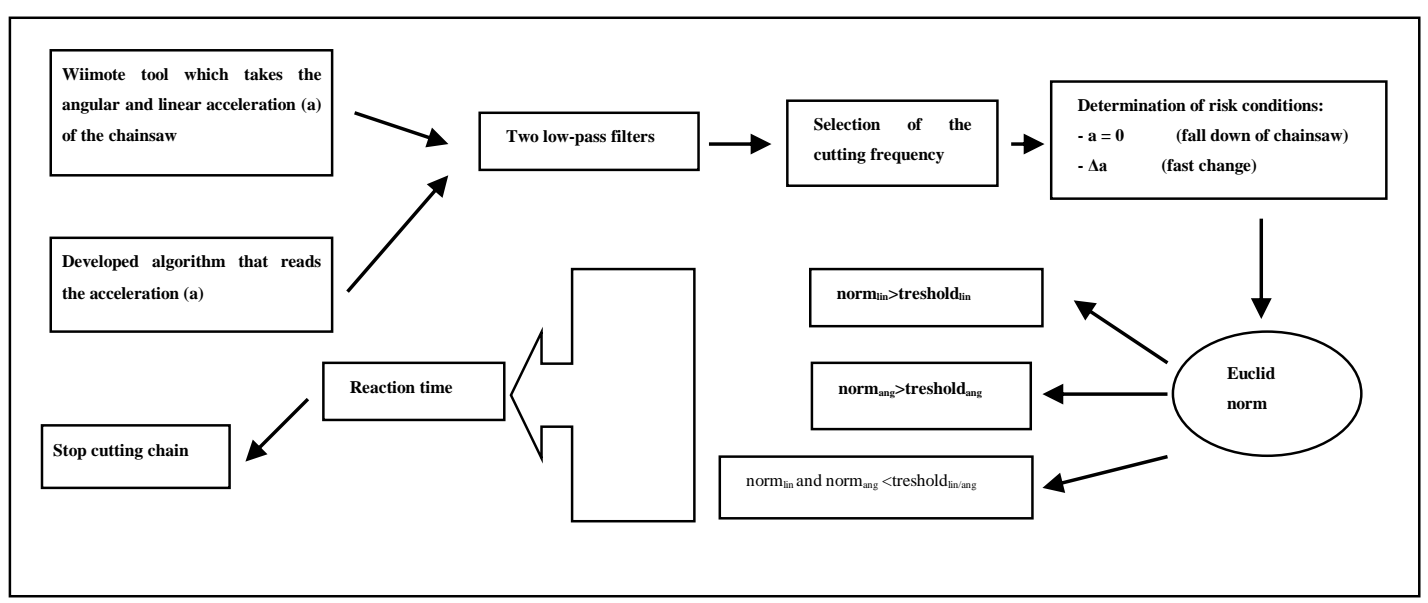

Figure 2 - The scheme of algorithm steps

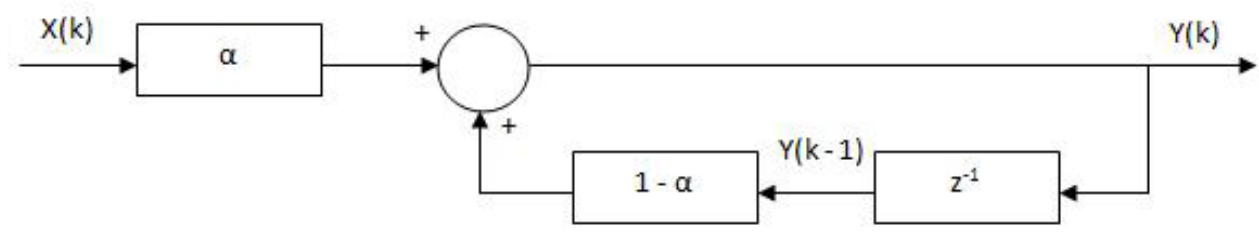

Figure 3 - The scheme of a low-pass filter ( $\alpha=$ parameter with range $0-1$;

$\mathrm{X}=$ Laplace transformed in input; $\mathrm{Y}=$ Laplace transformed in output; $\mathrm{k}=$ sample; $\mathrm{z}=$ coordinate (or $\mathrm{x}$ and $\mathrm{y})$ ).

In all chainsaws the chain brake is activated if the pressure is applied against the guard or when, in the event of a kickback, the operator's hand strikes the lever. In chainsaws equipped with electric motor the chain movement will be stopped by cutting off the power supply; in chainsaws driven by a 2 -stroke motor, a band brake is applied on the clutch drum. issues.

Filtering in this application is crucial because of the following conflicting

Undesired stops due to high frequency acceleration in the normal regime should be avoided and this requires a low pass filter with a proper cut-off frequency;

- Low pass filters introduce a delay in the reaction of the stopping mechanism which has to be small enough.

Obviously (and unfortunately) delay increases, if the cut of frequency decreases. Therefore the trade-off in the choice of the filter and its tuning is of fundamental importance. In this case, the best type of filters among the tested ones is a bi-dimensional Butterworth filter as in shown in Fig. 4 along with a dead-zone device. The filter ideally eliminates all frequencies above a certain assigned cut-off frequency, although in practice this is true only for ideal filters. 
The Buttherworth filter is a good solution in term of low-frequency selectivity and the cut off-frequency of such filter is $f c=\omega_{0} /(2 \square)$ where $\omega_{0}$ is a design parameter.

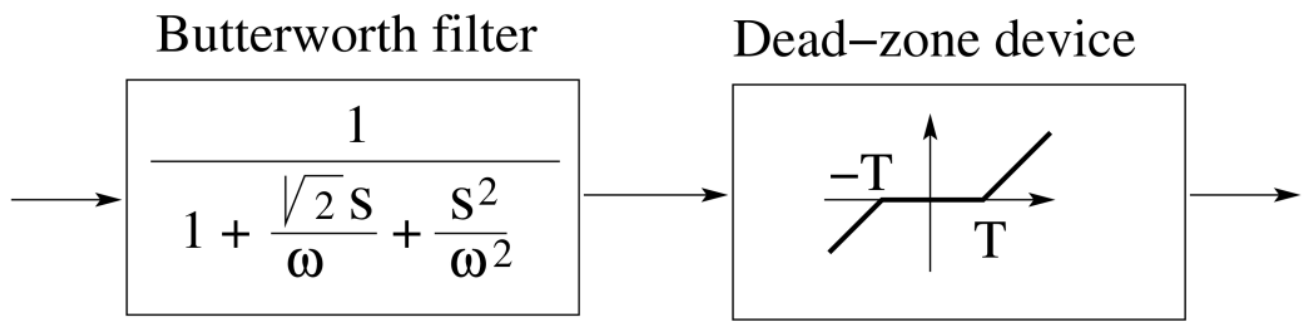

Figure 4 - The blocking logic: Butterworth filter with dead-zone device.

The filter alone does not work and it must be equipped by a dead-zone device (see Fig. 4) which cuts all signals below a certain amplitude T. The combined action of the two provides good results in terms of selectivity and sensibility.

The previous overall blocking logic device has been numerically simulated. A sensor signal of the form has been considered

$a=a_{c}+a_{1} \cos \left(\omega_{1} t\right)+a_{2} \cos \left(\omega_{2} t\right)+a_{3} \cos \left(\omega_{3} t\right)$

where

- c, is the constant component of the acceleration to be detected;

- $\mathrm{a}_{1} \cos \left(\omega_{\mathrm{i}} \mathrm{t}\right)$, is an harmonic component of the acceleration;

We have adopted three harmonic components with the following data for the accelerations

$$
a_{1}=5 ; \quad a_{2}=3 ; \quad a_{3}=3
$$

and, denoting by $\mathrm{fi}=\omega \mathrm{i} /(2 \pi)$, we took the following data for the frequencies

$$
\mathrm{f}_{1}=5 ; \quad \mathrm{f}_{2}=3 ; \quad \mathrm{f}_{3}=3
$$
$5 \mathrm{~m} / \mathrm{s}^{2}$.

We adopted $\mathrm{f}_{0}=4$ (then $\omega_{0}=8 \pi$ ) as cut-off frequency and a threshold of $\mathrm{T}=$

In Fig. 5 and Fig. 6 we can see the overall acceleration, the acceleration signal processed by the Butterworth filter, and the overall processed signal which does not appear in Fig. 6 as expected).

In Fig. 5 we have reported the case in which the constant component of the acceleration is $a_{c}=6 \mathrm{~m} / \mathrm{s}^{2}$. The device recognizes the potential dangerous situation and blocks the saw. The reaction time is about 0.1 s. In Fig. 6 the system is simulated under the same conditions with the only difference that the constant component of the acceleration is now $a_{c}=4 \mathrm{~m} / \mathrm{s}^{2}$ so no potential danger is detected. 


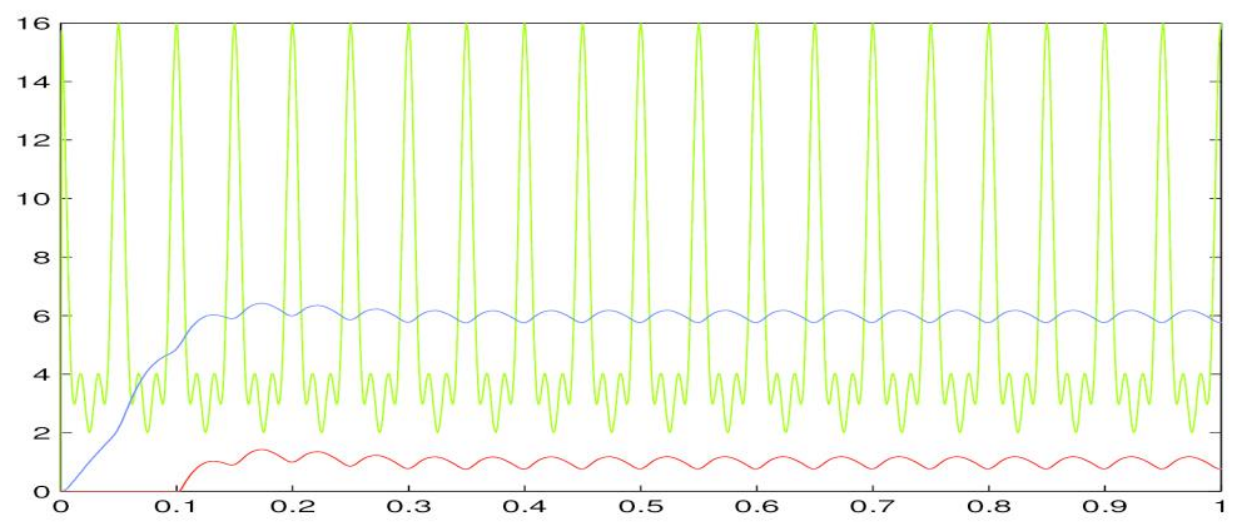

Figure 5 - The simulation of a chain-stop. Overall acceleration (green), the acceleration signal processed by the Butterworth filter (blue), and the overall processed signal (red)

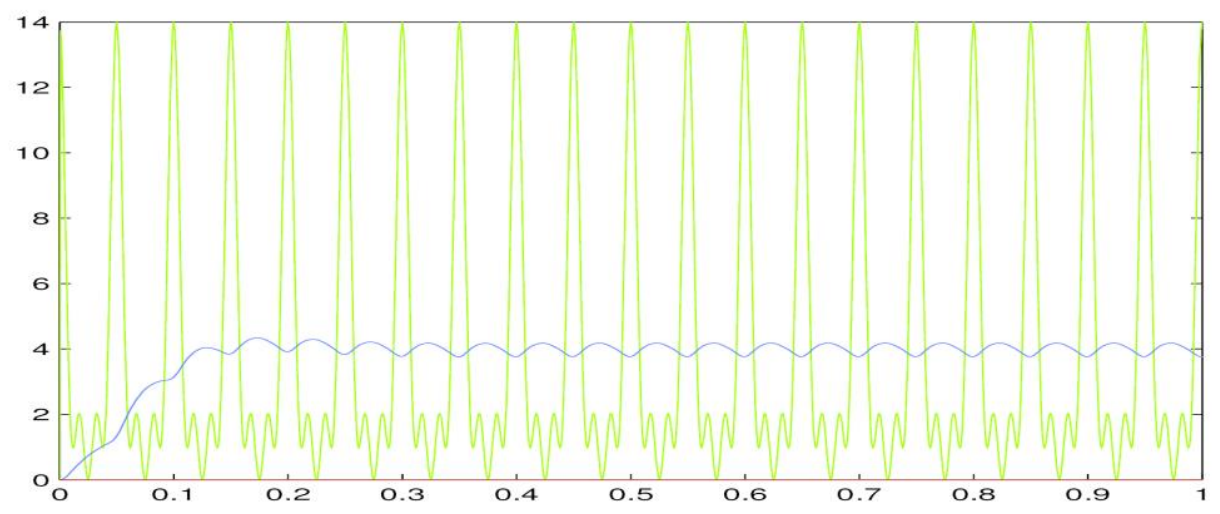

Figure 6 - The simulation of a chain-stop. Overall acceleration (green), the acceleration signal processed by the Butterworth filter (blue)

In the realized prototype in the case of electric motor the alarm system operates by acting on a potentiometer, in the case of a 2 -stroke motor the blockage will be integrated on the existing chain brake with an insertion of a mechanic piston activated by the alarm system.

A cordless electric chainsaw, Black \& Decker GKC1817, 18-V 8-in was used in the tests. All characteristics of the used electric chainsaw are present in Table 1.

\begin{tabular}{|c|c|c|}
\hline Voltage & $\mathrm{Vdc}$ & 18 \\
\hline Battery capacity & $\mathrm{Ah}$ & $1.7-1.5 \mathrm{NiCd}$ \\
\hline Battery mass & $\mathrm{kg}$ & 0.8 \\
\hline Charging time & $\mathrm{h}$ & 8 \\
\hline
\end{tabular}




\begin{tabular}{|c|c|c|}
\hline No load chain speed & $\mathrm{m} / \mathrm{s}$ & 3.1 \\
\hline Guide bar length & $\mathrm{cm}$ & 20 \\
\hline Mass & $\mathrm{kg}$ & 2.8 \\
\hline
\end{tabular}

Table 1 - The technical data of the GKC1817 chainsaw

Data were collected by a Wiimote controller (Nintendo ${ }^{\mathrm{TM}}$ ). Before starting the tests we defined the necessary calibration parameters in order to calculate all accelerations. From the Wiimote output for Wiimote reported values 0 to 999 we found these values:

- the value 490 is equal to linear acceleration ( $\mathrm{x}$ and y axes) zero (acclin=0);

- the value 590 is equal to linear acceleration ( $\mathrm{z}$ axes) $\mathrm{g}$ (acclin=9.8 m/s).

The test for the control the acceleration level were carried out cutting off different types of wood as reported in Table 2.

\begin{tabular}{|c|c|c|c|}
\hline Wood & $\begin{array}{c}\varnothing \text { wood } \\
(\mathrm{cm})\end{array}$ & $\begin{array}{c}\text { Replicates } \\
\text { (n.) }\end{array}$ & Mode of cutting \\
\hline Soft (poplar) & 4.0 & 29 & Up-down (lower cutting chain) \\
\hline Medium soft (fir) & 3.3 & 16 & Up-down (lower cutting chain) \\
\hline Hard (oak) & 5.8 & 10 & Up-down (lower cutting chain) \\
\hline Hard (oak) & 5.8 & 10 & Down-up (upper cutting chain) \\
\hline Hard (oak) & 5.8 & 10 & $\begin{array}{c}\text { Up-down (lower cutting chain, } \\
\text { near to top of guide bar) }\end{array}$ \\
\hline Hard (oak) & 5.8 & 10 & $\begin{array}{c}\text { Down-up (upper cutting chain, } \\
\text { near to top of guide bar) }\end{array}$ \\
\hline
\end{tabular}

Table 2 - The cut simulation test

To optimize the alarm signals it was necessary to set-up the parameters in order to have the correct sensitivity of the selected parameters as follows:

1. cut frequency of linear accelerations: cfSlin;

2. cut frequency of angular accelerations: cfSang;

3. linear threshold: thlin;

4. angular threshold: thang;

5. fall threshold: thfall. 


\begin{tabular}{|c|c|c|c|}
\hline Wood & $\begin{array}{c}\varnothing \text { wood } \\
(\mathrm{cm})\end{array}$ & $\begin{array}{c}\text { Reply } \\
(\mathrm{n} .)\end{array}$ & Kind of cutting \\
\hline Hard (oak) & 5.8 & 10 & Up-down (lower cutting chain) \\
\hline Hard (oak) & 5.8 & 10 & Down-up (upper cutting chain) \\
\hline Hard (oak) & 5.8 & 10 & $\begin{array}{c}\text { Up-down (lower cutting chain, } \\
\text { near to top of guide bar) }\end{array}$ \\
\hline Hard (oak) & 5.8 & 10 & $\begin{array}{c}\text { Down-up (upper cutting chain, } \\
\text { near to top of guide bar) }\end{array}$ \\
\hline nothing & - & 10 & Falling chainsaw \\
\hline
\end{tabular}

Table 3 - Selected settings for sampled parameters at $100 \mathrm{~Hz}$ by Wiimote

\section{Results}

The developed algorithm is capable to distinguish these risks situations:

- $\quad$ slipping of the operator;

- falling of the operator;

- falling of the chainsaw;

- $\quad$ kick back of the chainsaw;

- $\quad$ any other fast movement of the chainsaw or of the operator.

The algorithm calculates the vectorial norm of the linear and angular acceleration (Equation. 2 and 3).

$$
\begin{gathered}
\operatorname{norm}_{l i n}=\sqrt{\left.a_{l x}^{*}(t) a_{l x}^{*}(t-1)\right)^{2}+\left(a_{l y}^{*}(t)-a_{l y}^{*}(t-1)\right)^{2}+\left(a_{l z}^{*}(t)-a_{l z}^{*}(t-1)\right)^{2}} \\
\operatorname{norm}_{\text {ang }}=\sqrt{\left.a_{a x}^{*}(t) a_{a x}^{*}(t-1)\right)^{2}+\left(a_{a y}^{*}(t)-a_{a y}^{*}(t-1)\right)^{2}+\left(a_{a z}^{*}(t)-a_{a z}^{*}(t-1)\right)^{2}}
\end{gathered}
$$

The Euclid norm sphere delimits a space where the chainsaw can be moved. If, in this delimited space the chainsaw goes below the conditions showed in Fig. 2, the Wiimote stops the potentiometer of the electric chainsaw. 

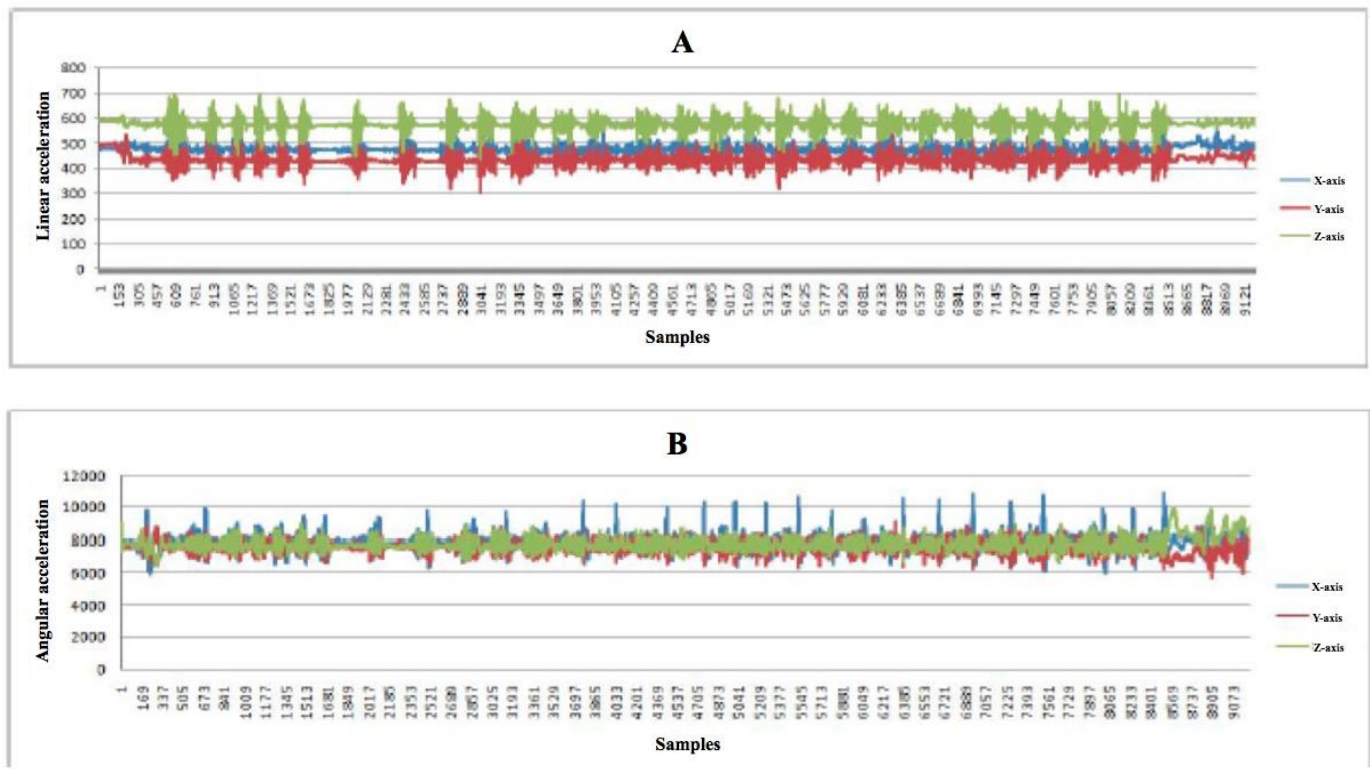

Figure 7 - Linear (A) and angular (B) acceleration with normal cutting of soft wood (up-down movements with bottom cutting chain)

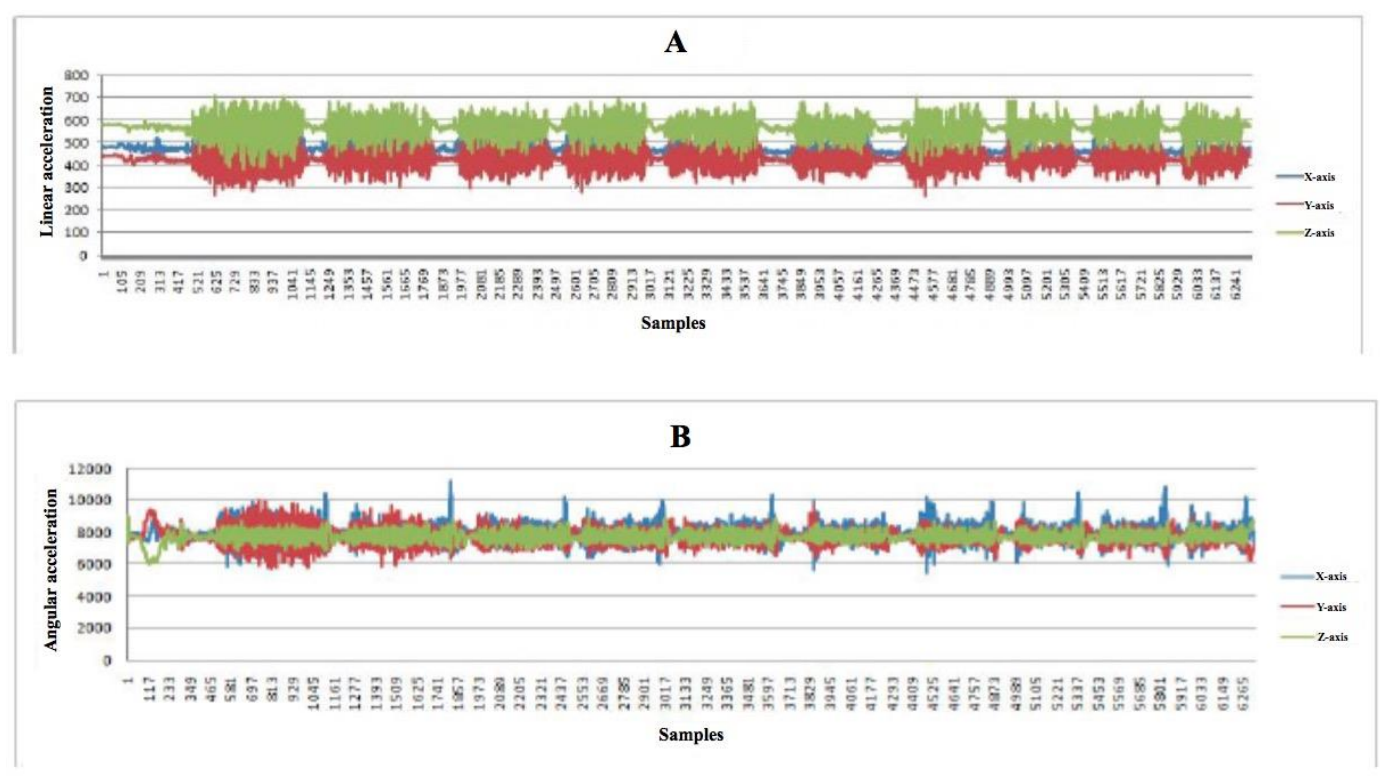

Figure 8 - Linear (A) and angular (B) acceleration with normal cutting of hard wood (up-down movements with bottom cutting chain) 

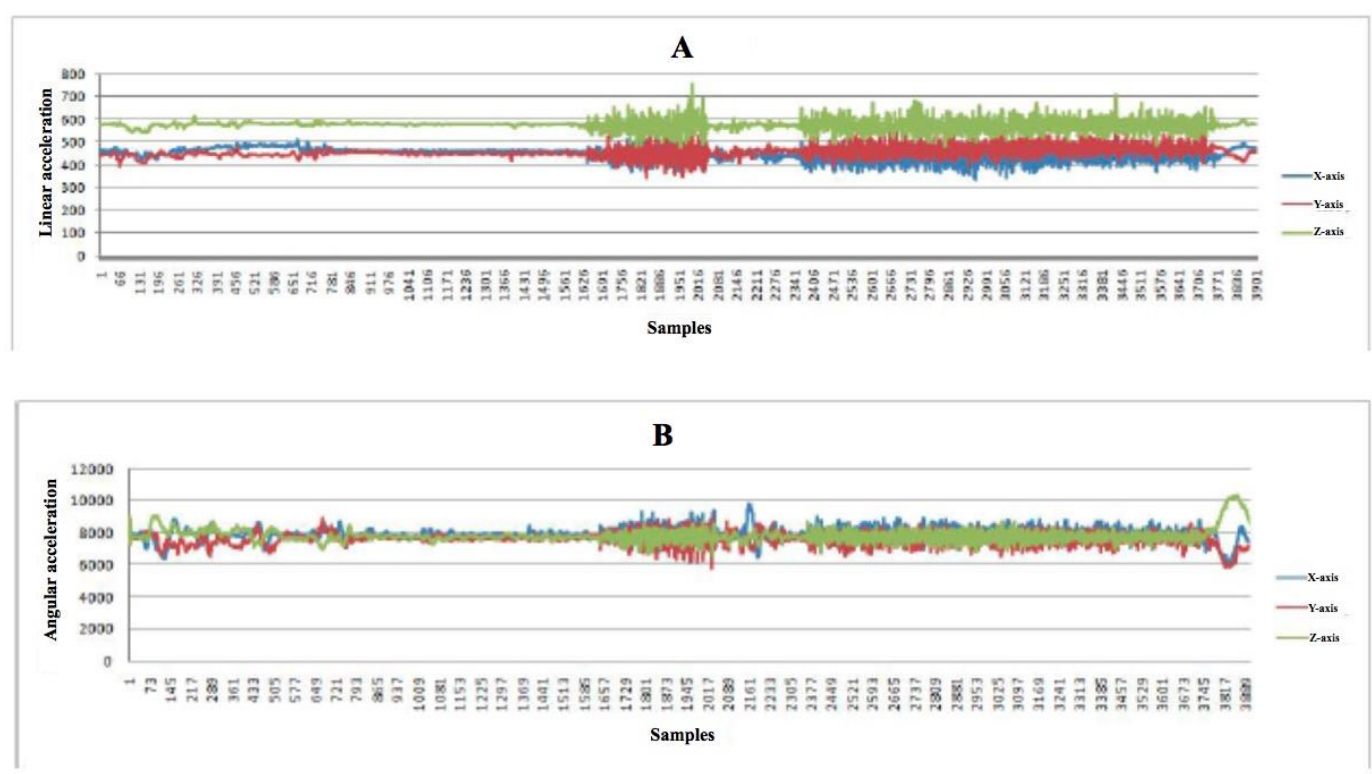

Figure 9 - Linear (A)) and angular (B) acceleration with down-up cutting of hard wood (up-down movements with bottom cutting chain)

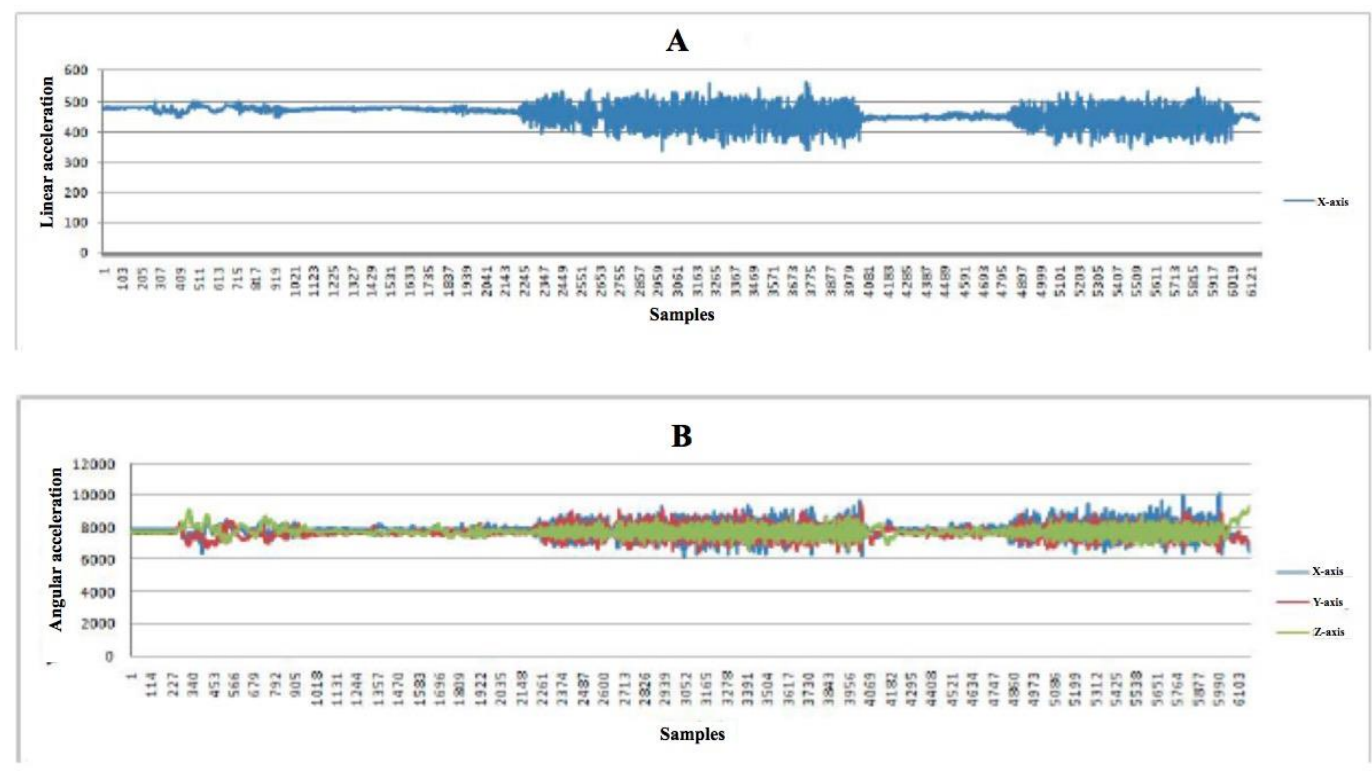

Figure 10 - Linear (A) and angular (B) acceleration with down-up near to top of guide bar cutting to hard wood (up-down movements with bottom cutting chain)

The test carried out to verify the correct correlation of the accelerations and alarm signal showed:

- that the normal cutting with soft wood has a sufficient uniform linear and angular acceleration (Fig. 7); 
- the normal cutting with hard wood has a good uniformity as to linear and angular accelerations, but also has more amplitude then in the previous case (fig. $8)$;

- $\quad$ the cutting in down-up mode with upper cutting chain part do not show more amplitude in accelerations than normal cutting (fig. 9);

- the cutting in up-down or down-up mode near to top of guide bar the acceleration held a large amplitude but not so great to activate the alarm signal (fig. 10).

In conclusion, when the chainsaw works in different mode but always within a normal condition the alarm signal is not activated.

The test carried out for setting parameters must result optimized to the alarm signals and not to its sensitivity because the chainsaw should not stop so easily and promptly.

All collected data were reported in nine different combinations both with linear and angular accelerations and the number of reported errors (from 0 to $>50$ ). During wood cutting the alarm does not need to be activated and must be considered only in those combinations where the value error is equal to zero (Table 4 and 5).

\begin{tabular}{|c|c|c|c|c|}
\cline { 3 - 5 } \multicolumn{2}{c|}{} & \multicolumn{3}{c|}{ Linear cut frequency } \\
\cline { 3 - 5 } \multicolumn{2}{c|}{} & 0.10 & 0.39 & 0.60 \\
\hline \multirow{2}{*}{$\begin{array}{c}\text { Linear } \\
\text { threshold }\end{array}$} & 3 & 0 & $>50$ & $>50$ \\
\cline { 2 - 5 } & 5 & 0 & 0 & $>50$ \\
\cline { 2 - 5 } & 6 & 0 & 0 & 39 \\
\hline
\end{tabular}

Table 4 - Linear cut frequency (cfSlin) and threshold (thlin) during hard wood cut

\begin{tabular}{|c|c|c|c|c|}
\cline { 3 - 5 } \multicolumn{2}{c|}{} & \multicolumn{3}{c|}{ Angular cut frequency } \\
\cline { 2 - 5 } \multicolumn{2}{c|}{} & 0.05 & 0.45 & 0.60 \\
\hline \multirow{3}{*}{$\begin{array}{c}\text { Angular } \\
\text { threshold }\end{array}$} & 50 & 1 & $>50$ & $>50$ \\
\cline { 2 - 5 } & 250 & 0 & 0 & 1 \\
\cline { 2 - 5 } & 450 & 0 & 0 & 1 \\
\hline
\end{tabular}

Table 5 - Angular cut frequency (cfAng) and threshold (thang) during hard wood cut

In the same way we set the parameters also in others different types of cutting (up-down cutting chain, near to top of guide bar and down-up).

Regarding the chainsaw falling down we considered that a body fall down 
when the linear acceleration is equal to zero. The threshold value for observation of this condition must be very little and we set it for the Wiimote to a value of 40 . The parameters set-up after tests is reported in Table 6.

\begin{tabular}{|c|c|}
\hline Linear cut frequency (cflin) & 0.40 \\
\hline Angular cut frequency (cfang) & 0.45 \\
\hline Linear threshold (thlin) & 5 \\
\hline Angular threshold (thang) & 250 \\
\hline Falling threshold (thfall) & 40 \\
\hline
\end{tabular}

Table 6 - Parameters set-up on Wiimote

\section{Conclusions and perspectives}

The device demonstrated a correct behavior in dangerous situations and it is considered that it use can be extended to combustion engine chainsaws, as well as to other portable equipment used in agriculture and forestry operations. The Wiimote is simple and economical device which is possible to install on the chainsaw for collection of acceleration and position data. The used algorithm allows an efficient control of data processing and of the signal sending for the blockage of the cutting chain. Overall, the idea is based on Wiimote device and on an algorithm based on Euclid norm which was patented in year 2011 (Blanchini et al., 2001). This patent allows us to have also chances for further development as well as its real application on chainsaw.

\section{References}

[1] F. Blanchini, R. Lombardo, G. Battiston, S.R.S. Cividino, J. Pighin, R. Gubiani, G. Pergher, Patent rif. Glp's ref. A3-8816, State, Italy, filling No. UD2011A000039, Filling date: 15/03/11, International classification B27G (2011).

[2] N.M. Bracchetti, C. Lombardini, N. Magagnotti, E. Marchi, F. Neri, G. Picchi, R. Spinelli. Relating safety, productivity and company type for motor-manual logging operations in the italian Alps, Accidents Analysis and Prevention, 42 (2010), no. 6, 2013-2017. http://dx.doi.org/10.1016/j.aap.2010.06.011 
[3] R.S.S. Cividino, R. Gubiani, G. Pergher, D. Dell'Antonia, E. Maroncelli, Accident investigation related to the use of chainsaw, Journal of Agricultural Engineering 2013; volume. XLIV (s1):e137, 686-688.

[4] A.J. Lefort, C.F. De Hoop, J.C. Pine, B.D. Marx, Characteristics of injuries in the Logging Industry of Louisiana, USA: 1986 to 1998, International Journal of Forestry Engineering, 14 (2003), no. 2, 75-89.

[5] S. Axelsson, The mechanization of logging operations in Sweden and its effects on occupational safety and health, International Journal of Forest Engineering, 9 (1998), no. 2, 25-31.

[6] J. Hartfield, First Standardized Federal accident statistic - Analysis of accident data of the State Forest Services in Germany, Proceedings of the seminar on safety and health in forestry are feasible held in Konolfingen, Switzerland, (1997), 105-126.

[7] P. Herfurth, H. Krämer, D. Uppert, Explanation and evaluation of kick-back measurements on chainsaw, Forsttechnische Informationen, (1995), no. 3, 33-34.

Husqvarna, TrioBrakeTM AB. SE-104 25 Stockholm S:t Göransgatan 143 +46-3614 6500 +46-887396450556000-5331, Sweden.

www.husqvarna.com

[8] C. Jordan, A. Friese, P. Heywood, A. Barber. Patent Application Number: EP20100195647 Publication Date: 06/20/2012 Filing Date: 12/17/2010, International classification B27B 17/08.

[9] I. Potočnik, T. Pentek T, A. Poje, Severity analysis of accidents in forest operations, Croatian Journal of Forest Engineering, 30 (2009), no. 2, 171-184.

[10] G.T. Robertson, C.W. Suggs, Construction and evaluation of a chainsaw kickback simulator, Applied Engineering in Agriculture, 7 (1991), no. 2, 153-157. http://dx.doi.org/10.13031/2013.26224

[11] R.M. Shaffer, J.S. Milburn, Injuries on feller-buncher/grapple skidder logging operations in the Southeastern United States, Forest Products Journal, 49 (1999), no. 7/8, 24-26.

[12] B. George, H. Zangl, T. Bretterklieber, A warning system for chainsaw personal safety based on capacitive sensing, IEEE Conference Sensors, 2008, 419-422. http://dx.doi.org/10.1109/icsens.2008.4716467 
[13] M. Cecchini, A. Colantoni, R. Massantini, D. Monarca, Estimation of the risks of thermal stress due to the microclimate for manual fruit and vegetable harvesters in central Italy, Journal of Agricultural Safety and Health, 16 (2010), no. 3, 141-159. http://dx.doi.org/10.13031/2013.32040

[14] A. Marucci, B. Pagniello, D. Monarca, M. Cecchini, A. Colantoni, P. Biondi, Heat stress suffered by workers employed in vegetable grafting in greenhouses, Food, Agriculture and Environment, 10 (2012), no. 2, 1117-1121.

[15] M. Cecchini, F. Cossio, A. Marucci, D. Monarca, A. Colantoni, M. Petrelli, E. Allegrini, Survey on the status of enforcement of European directives on health and safety at work in some Italian farms, Food, Agriculture and Environment, 11(2013), no. 3\&4, 595-600.

[16] D. Monarca, M. Cecchini, A. Colantoni, G. Menghini, R. Moscetti, R. Massantini, The evolution of the chestnut harvesting technique, Acta Horticulturae II European Congress on Chestnut, 1043 (2014), 219-224. http://dx.doi.org/10.17660/actahortic.2014.1043.29

[17] D. Monarca, R. Moscetti, L. Carletti, M. Cecchini, A. Colantoni, E. Stella, G. Menghini, S. Speranza, R. Massantini, M. Contini, A. Manzo, Quality maintenance and storability of chestnuts manually and mechanically harvested, Acta Horticulturae II European Congress on Chestnut, 1043 (2014), 45-152. http://dx.doi.org/10.17660/actahortic.2014.1043.19

[18] A. Marucci, D. Monarca, M. Cecchini, A. Colantoni, S. Di Giacinto, A. Cappuccini, The heat stress for workers employed in a dairy farm, Journal of Food, Agriculture \& Environment, 11 (2013), no. 3\&4, 20-24.

[19] K. Boubaker, A. Colantoni, E. Allegrini, L. Longo, S. Di Giacinto, D. Monarca, M. Cecchini, A model for musculoskeletal disorder-related fatigue in upper limb manipulation during industrial vegetables sorting, International Journal of Industrial Ergonomics, 44 (2014), 601-605. http://dx.doi.org/10.1016/j.ergon.2014.03.005

[20] A. Colantoni, L. Longo, P. Biondi, B. Baciotti, D. Monarca, L. Salvati, K. Boubaker, S.R.S. Cividino, Thermal stress of fruit and vegetables pickers: Temporal analysis of the main indexes by "predict heat strain" model, Contemporary Engineering Sciences, 7 (2014), no. 35, 1881 - 1891. http://dx.doi.org/10.12988/ces.2014.410201

[21] S. Di Giacinto, A. Colantoni, M. Cecchini, D. Monarca, R. Moscetti, R. Massantini, Dairy production in restricted environment and safety for the workers, Industrie Alimentari, 530 (2012), 5-12. 
[22] A. Colantoni, A. Marucci, D. Monarca, B. Pagniello, M. Cecchini, R. Bedini. The risk of musculoskeletal disorders due to repetitive movements of upper limbs for workers employed to vegetable grafting, Food, Agriculture and Environment, 10 (2012), no. 3\&4, 14-18.

[23] M. Cecchini, A. Colantoni, R. Massantini, D. Monarca, The risk of musculoskeletal disorders for workers due to repetitive movements during tomato harvesting, Journal of Agricultural Safety and Health, 16 (2010), 87-98. http://dx.doi.org/10.13031/2013.29593

Received: March 30, 2015; Published: October 16, 2015 